\title{
Occupational Stress among the Teachers of the Higher Secondary Schools in Madurai District, Tamil Nadu
}

\author{
Dr. S.S.Jeyaraj \\ Business Studies Lecturer, Department of Accounting and Commerce,International Universal (Junior College) \\ School, Jakarta, Indonesia.
}

\begin{abstract}
The aim of the study is to determine the Occupational Stress level of Government and Aided Higher Secondary School Teachers living in different socio-cultural and economic situations. The scale used in the study has been developed by researches. 185 Aided school teachers and 120 Government teachers have participated in the present study. At the end of the study it was seen that Aided school teachers have more occupational stress levels than Government school teachers. There is a meaningful difference in the stress level points of Government and Aided Higher Secondary Teachers. Policy makers are advised to analyse the teacher training and assessment system with the assumption that personal and social characteristics and working conditions may have an effect on teacher occupational stress. Results also showed that teachers who reported greater stress were less satisfied with teaching, reported greater frequency of absences and a greater number of total days absent, were more likely to leave teaching (career intention), and less likely to take up a teaching career again (career commitment).Implications for further research are also discussed.
\end{abstract}

Keywords: Inter-role distance, Role Ambiguity, Role Stagnation, Role Stress, Self-role distance, Teacher Occupational stress.

\section{Introduction}

\subsection{Introduction}

Stress is a common feature in our lives, especially as the pace of development increases. Work is a common term which is applied for all sorts of occupation. It is a basic condition for most people and is an important component of the atmosphere for human survival. It is also a major element for the development of the individual as well as the economy of the nation. Many adults spend half of their lives in work related activities. It is natural to experience work related stress on tension or strain in the body or the mind if there is no release or outlet for the bent-up feelings. A phrase 'stress collapses everything' has a prominent place in the minds of millions. It is a silent killer in the modern age.

The word 'stress' is defined by the Oxford Dictionary as "a state of affairs involving demand on physical or mental energy". In medical parlance 'stress' is defined as a perturbation of the body's homeostasis. Extreme stress conditions are detrimental to human health. But in moderation stress is normal and in many cases, proves useful. An occupational stress can be caused by too much or too little work, time pressure and deadlines, fatigue from physical strains of work environment, excessive travelling, long hours, having to cope with changes in work. [1]

An occupational stress is any force that pushes a psychological or physical factor behind its range of stability, producing a strain within the individuals. Knowledge that stress is likely to occur constitutes a threat to the individual. A threat can cause a strain because of what it signifies to the person. As occupational stress begins to take toll on the body and mind, a variety of symptoms can result.2]

Working in organisations not only provides individuals with life sustaining income but also exerts its own pressures on them. This can ultimately have negative consequences both for achieving the goals of the organisation and meeting the needs of the individuals working in them. Thus, the work environment is a source of social and psychological stress, which has harmful effects on the well-being of the employees. Stress in general and occupational stress in particular is universal and frequently disabling human phenomenon. Stress arising at work has detrimental effect on the behaviour of people, which ultimately results in personal and organisational inefficiency. Occupational stress can be described as a condition where occupation related factors interact with the worker to change (disrupt/ enhance) his or her psychological or physiological condition, so that the person's mind and/or body is forced to deviate from its normal way of functioning. [3]

\subsection{Statement of the Problem}

The progress of a nation is limited to its productive capacity, which in turn depends upon the calibre of its higher secondary education. The education system in general and the higher secondary education system in particular are instruments to develop the human capital as economic assets for wealth generation and also as social assets for improving the quality of the life of the people. The education system should provide scope for 
understanding several major socio-economic changes affecting the society that include global economic integration, national economic reforms, changing demographic pattern, increased school's enrolment reduced drop-out rate, social norms favouring women and weaker sections, increasing environmental consciousness, changing family finances, demands of labour market and so on.

The strategy for development of higher secondary education would have to take these trends in determining the future mission. However there is little consensus between different professional groups regarding its etiology or how to tackle it. Based on a review of international research, it is concluded that teacher occupational stress is a real phenomenon and that high levels are reliably associated with a range of casual factors, including those intrinsic to teaching, individual vulnerability and systematic influences. Limitations with the current research base of teacher occupational stress are identified. There is a reasonable understanding of the etiology of teachers' occupational stress, but little is known about the effects of reducing or mediating the impact of stressors. There are very few studies of effective interventions and none involving large samples or long-term follow-up. There are serious problems in generalizing finds from stress-management in other occupational sectors, as well as addressing these gaps in our understanding. Future research based on a social representations approach is needed to allow teachers and stress management practitioners a shared understanding of stress.

For an individual any environment has a certain degree of stress, though of varying duration. When stress is sustained for a long period of time, the problem becomes significant. Since India is a labour surplus economy, getting employment is a must for all not only for the self but also to become useful to the country. Entering into a wrong job and hanging on to it for the obvious reason of making a living is quite common in Indian economic scene. Such a situation only adds to the occupational stress. The higher secondary teacher is to go on periodic self-decreased vacations in the form of absenteeism. School teachers are no exception to this. The individuals entering into teaching field are professionals. They enter into professions and then they professionalize themselves and so they find themselves at loggerheads. Further, in teaching jobs are structured in a way that a worker is simultaneously exposed to both overload and acute time pressure. Generally people under stress express their frustration through some common ways like excessive criticism of government and management and displaying inability to get along with others. A general knowledge of this behaviour in higher secondary school teachers increases the understanding of individuals as well as of groups became, if furnishes one with certain principles. These principles help in recognition of the symptoms of distress and indicate the kind of behaviour one may expect so that steps can be taken to deliberately shape the environment to elicit expected responses. But, in the education department such individual behaviour cannot be easily identified, as individual performance cannot be quantitatively measured as precisely as in teaching field. Symptoms of stress take a long time to erupt. Once it erupts, it not only affects the individual concerned but also the co-workers through strained interpersonal relations and ultimately affects the student's education which forms the very core for the success of education department. Hence occupational stress situations and their perceived impact on higher secondary school teachers are taken up for the present study. The researcher has made an attempt to study the occupational stress among higher secondary school teachers of Madurai district.

\subsection{Review of Literature}

The south Australian Institute of Teachers(1971) in their study" Factors in Teaching causing satisfaction and dissatisfaction amongst teachers in south Australia" indicated that the lack of time was the case of either moderate or a great deal of dissatisfaction in job and 75.1 per cent of respondents' negative community attitudes were also identified as a cause of teacher stress.

Weiskopf,P. (1980) in his study on "Burnout Among teachers of Exceptional children" reveals the high correlation between burnout scores and degree of job satisfaction and performance, and also found significant relationship between such scores and negative perceptions by teachers of their own power to influence work situations.[4]

Pettegrew L.S. and Wolfie, G.E. (1982) in their investigation on "Validating Measures of Teachers Stress" explain that the contract validity of several measures of teachers stress and suggested that the phenomenon requires multivariate assessment. Further the researchers suggest that the survey questionnaire made no attempt to measure, account for or acknowledge the effects of stressors from sources beyond the school environment. [5]

Cunninghum, W.G. (1983) in his study on "Teachers Burnout Solutions for the 80's review of literature" explains that organizational stress factors linked with physical, emotional and attitudinal exhaustion manifest in physical and emotional illnesses. Decreases in job satisfaction and subsequent poor performance have been linked to occupational stress burnout. [6]

Billings and Moos (1984) in their study on "Coping Stress and Social Resources among Adults with Unpopular Depression" explain the roles of stress, social resources, and coping among men and women entering treatment for depression. They found that work stressors had greater impact of women than men. [7] 
Frese (1985) in his article entitled "stress at Work and Psychosomatic Complaints: A Casual Interpretation" based on three studies with partly overlapping samples reported results, showed correlation between work stress and psychosomatic complaints. Though the study primarily aimed at studying the effect of those variables in the relationship between stress and its outcomes, the results showed that the correlation of stress and psychosomatic complaints was not spurious, and that stress indeed was a cause of somatic complaints. The study concluded that the objective conditions of work stress influence the development of subjective stress and psychosomatic complaints. [8]

Manthei and Solman (1988) In their study on "Comparative Teachers Stress and Negative Outcomes in Canterbury State Schools" focuses the study on New Zealand and N.S.M. teachers, identified seven structural factors which led to teachers stress like, pupil recalcitrance, poor remuneration, curriculum demands, low professional recognition, poor working environment, community antagonism and time demand and lack of time for adequate, preparation of assistance with individual pupil difficulties. [9]

Sharma, V.and Sharma,S. (1989) in their study on "Organizational Role Stress and Anxiety: A comparative Study of Bureaucrats and Technocrats", analyzed the nature and Magnitude of the relationship of role stress with general and job anxiety among bureaucrats and technocrats. Roll stress correlated positively with both the outcomes among technocrats and with job anxiety among bureaucrats. With regard to specific stressors also it was found that technocrats were more vulnerable to stress. [10]

Piercce, C.M.B. and Molloy G.N. (1990) in their article entitled on "Relationship between School Type, Occupational Stress, Role perceptions and Social Support" highlights major findings of this study are reported in rank order from greatest to least occupational stress factors like work load, time management, salary, resources comment in the media, interaction with colleagues and managing student behaviors. [11]

Kaldenberg and Becker (1992) in their study on "Workload and Physiological Strain" examined that the extent to which psychological strain was related to in congruence between workload preference and work load experience. Psychological strains studied sere self esteem and job satisfaction. They found a curvilinear relationship between person-environment fit and psychological strain. Both self-esteem and job satisfaction were higher for those with congruent fit between typical and preferred workload. Lower for those with incongruent fit. The study also found that people who work in a setting that provides autonomy and the opportunity to control the flow of work tended to have the most congruent fit between preferred and typical hours of workload. [12]

Morton et al (1997) in their study on "Student Teacher Anxieties related to Class Management, Pedagogy, Evaluation and Staff Relations" found that among the sources of tress for student teachers, evaluation apprehension was the greatest, although it declined following teaching practice, suggesting that it is reduced by exposure and positive experiences of observation feedback. [13]

Pitchers R.T. and Soden R. (1998) I their study on "Scottish and Australian Teachers Stress and Strain" highlight the role overload as a significant stressors. They assessed levels of strain, organizational roles and stress in 322 Australian and Scottish Vocational and further education lectures. The researchers have concluded that strain was found to be average in both national groups, but there were high levels of stress, with role overload emerging as the major cause. [14]

Lewis R. (1999) in his study on "Teachers Coping with the stress of Class Room Discipline" explains that the teachers' estimations of stress arose from being unable to discipline pupils in the way they would prefer. The researcher has concluded that the class room discipline is also a significant source of stress. [15]

Friedman, I.A. (2000) in his study on "Burnout in Teachers Shattered Dreams of Impeccable Professional Performance" examined the self reports of newly qualified teachers and described his findings as the Shattered dreams of idealistic performance. The researchers has concluded that the respondents revealed sharp declines in self-efficacy as they found that they could not live up to their ideal performances. [16]

Xiao Z., et al (2003) in their study on "Teachers Needs in China" reveal that during the past ten years or more, a majority of researchers job satisfaction in China have mainly focused on urban areas rather than on rural areas (Xiao \& Li, 2003) with more and more emphasis on education in rural areas, especially in areas of high poverty, recent studies have paid more attention to teacher job satisfaction in rural areas. [17]

Sargent, T. and Hannum, E. (2005) in their study on "keeping Teachers Happy job Satisfaction among Primary School Teachers in Rural North-west China" comparative study highlight an in-depth research on teacher job satisfaction in rural north-west China, in terms of community factors, school environment factors, and teacher characteristics. Their findings were mostly in alignment with previous studies, but contrary to their assumptions, however, teachers with greater workloads, felt more satisfied. Further more economic development was negatively connected with teacher's satisfaction. [18]

Pande, N. and Naidu, R.K. (1986) in their study on "Effort and Outcome Orientations as Moderators of Stress Strain, Relationship" describes the moderating effect of effort orientation and outcome orientation in the stress-strain relationship. Partial evidence for the moderating effect was found. Those high on outcome 
orientation had higher distress than those low on it. Those high on effort orientation reported fewer symptom when under stress than others. [19]

Jha,S.S. (1988) in his study on "Jobs Stress and Employee Strain in India Executives" explains the pattern of stress and strain in three work groups namely production, personnel and data processing divisions in an organization. Results indicated that job future ambiguity had negative effect on job satisfaction in all the three groups. The patter of stress in the three groups was different among different levels of management. Among different levels of managers, the diddle level managers had more role ambiguity than others did. [20]

Reddy, V.S. and Ramamurthi, P.V. (1991) in their study on "The Relation between Stress Experience on the Job-Age, Personality and General ability" analysed the influence of age, personality and general ability of the individual in the perception of stress. It was found that only age influenced the perception of stress. There was only very limited contribution of personality and general ability of the individual to the intensity of stress experience of the individual. [21]

Rajeswari, T.R. (1992) in her study on "Employee Stress: A Study with Reference to Bank Employees" found significant negative relationship between age and stress and also between experience and stress. This study also found negative correlation between number of members in the family and stress. The level of stress did not differ between different levels of workers namely officers, and clerks. [22]

Singh, A.K. and Sehgal, V. (1995) in their study on "Men and Women in Transition: Patterns of Stress, Strain and Social Relations" Highlight the patterns of stress and strain among men and women as well as single and dual career couples. They found that male and female managers did not differ significantly on various stress dimensions. Difference in gender was however found in strains. Women were characterized by anxiety, whereas men exhibited more symptoms of somatic problems comparing the single and dual couples. It was fund that male managers with spouses working experienced higher workload than managers whose spouses were not working. In strains also single career male managers had less irritability that dual career male managers din overall single career male managers had better psychological well-being than others did working women managers had better physical well-being that their working husband did but had poorer psychological wellbeing. [23]

Lewis,R. (1999) in his study on "Teachers Coping with the Stress of Classroom Discipline" examined that the teachers estimations of stress arising from being unable to discipline pupils in the way. They would prepare overall maintaining discipline emerged as a stressor, with those worst affected being teachers who placed particular emphasis on pupil empowerment. [24]

Farooq A.Shah (2003) in his study on "Role Stress in the Indian Industry: A Study of Banking Organisations" describes adequate explanation of stress, and its nature, dimensions, causes, manifestations and coping up strategies. It was observed that most of the employees experience medium to high level of stress at work. Role stagnation, inadequacy of role authority and role erosion is comparatively high rated dimensions of job stress. The study further reveals that employees belonging to the clerical cadre relatively experience more stress on most of the dimensions. [25]

Berhem et al (2004) in their study on "A New Model for Work Stress Patterns" describe that the role of ambiguity as the main source of work stress and self-knowledge as the main coping strategy to overcome work stress. Work stress is believed to be one of the most important factors affecting productivity. [26]

Lakhwinder Sing Kang (2005) in his study on "Stressors among Medical Representatives: An Empirical investigations" tries to investigate the various stressors related with the job of a medical representative. A sample of 140 medical representatives was taken for the purpose of the present study. The results showed interference of job in personal life, 'unsupportive collegues.' 'Work load' and 'continuous pressure for improved performance' have been found to be causing stress among the medical representatives. [27]

Anitha Devi (2006-7) in her study on occupational stress: A comparative Study of Worker in different Occupations" describes identifying the degree of life stress and role stress (LS \& RS) experienced by professional women. It also studies the effect of life stress and role stress on various demographic variables like age, experience and income. For the purpose of study, 180 women professionals (six different occupations) were chose. It was found that science and technology professionals and doctors experienced significantly greater life stress and role stress. [28]

Dhanalakhsmi (2008) in her study on "Actors Predicting Stress of Employees in a Public Transport Corporation" measures the level of stress of the transport corporation employees and also studies the factors that could predict stress. It is found that the employees experience moderate level of stress. Further, stress is predicted by working environment and safety and security. [29]

\subsection{Objectives of the Study}

This study is carried out to analyse occupational stress among the teachers of higher secondary schools in Madurai district in Tamilnadu. 
1. To analyze the factors influencing occupational stress among the higher secondary school teachers.

2. To study the demographic and academic characteristics among the higher secondary school teachers of government and aided schools.

3. To measure the levels of occupational stress among the higher secondary teachers of government and Aided schools.

\subsection{Scope of Study}

This study is limited to identify the occupational stress situation and perceived behaviour under such situations and also to assess the outcome of stress in the higher secondary teachers of Government and Aided Schools only. It does not include the partly aided, Adi-Dravidar welfare, Kallar reclamation and unaided higher secondary school teachers. A comparative study can be aimed between Government and Aided higher secondary teachers. Further it can be extended to those who are working in rural and urban area to obtain their perception too.

\subsection{Hypothesis}

The following null hypotheses were formulated Null Hypothesis - There is no significant relationship between the variables and level of occupational stress among the aided and government higher secondary school teachers. Alternative Hypothesis - There is a significant relationship between the variables and level of occupational stress among the aided and government higher secondary school teachers.

\subsection{Research Methodology}

The present study is based on both primary and secondary data. Primary data have been collected by conducting a survey among 305 sample higher secondary teachers comprising headmasters and higher secondary school teachers of government and aided schools. Secondary data have been collected from books, journals, newspapers, periodicals, reports, internet and unpublished records of Madurai District of Tamil nadu. Initial instrument was developed by generating 108 items after a thorough understanding of occupational stress among Aided and Government higher secondary school teachers of Madurai district in the state of Tamil nadu. The first part of the questionnaire was related to personal details of higher secondary teachers, second part relates with measuring of occupational stress among the teachers with the help of Chi-square test. All the closed-ended questions were designed to generate responses on a five point likert scale to measure the occupational stress indicated as 1 strongly disagree, 2 disagree, 3 no opinion, 4 agree and 5 strongly disagree. For the present study a pilot study was initiated with a sample of 50 higher secondary teachers which in the elimination of some unrelated items.

\subsection{Sampling Design}

A sample of 305 teachers was taken to meets the sample adequacy, for conducting factor analysis number of sample teachers for the study were selected from the total population. For the purpose of the study (305 Teachers) $30 \%$ per cent of the samples were selected. Sample teachers were selected by using simple random sampling from three segments by using lottery method because of easy accessibility and affordability. This study is limited to a particular teachers those who are handling the classes in higher secondary teachers in Aided and Government schools and none of the teachers those who are handling classes in below higher secondary level and unaided higher secondary school teachers. 305 completely filled in questionnaire were finalized, non response rate was negligible. Adequate care has been taken to avoid redundancy in data collection from the sample elements.

Table 1.1

Sample-size of higher secondary teachers and head masters

\begin{tabular}{|l|c|c|c|}
\hline \multicolumn{1}{|c|}{ Category } & Head Masters & $\begin{array}{c}\text { Higher Secondary School } \\
\text { Teachers }\end{array}$ & Total \\
\hline $\begin{array}{l}\text { Government } \\
\text { Schools }\end{array}$ & $23(19.20 \%)$ & $97(80.8 \%)$ & 120 \\
\hline Aided Schools & $17(9.2 \%)$ & $168(90.8 \%)$ & 185 \\
\hline Total & $40(13.2 \%)$ & $265(86.8 \%)$ & 305 \\
\hline
\end{tabular}

Source: Primary Data.

Table 1.1 shows that out of 305 higher secondary school teachers, 265 ( 86.8 per cent) are teachers and the remaining 40 (13.2 per cent) are head masters. Among the total teachers, 120 are belonging to government schools and the remaining 185 are belonging to aided schools. Among the 120 government school teachers, 97 (80.8 per cent) are teachers and the remaining 23 (19.20 per cent) are head masters. Among the 185 aided school teachers, 168 (90.8 per cent) are teachers and 17 (9.2 per cent) are head masters. 


\section{Analysis And Interpretations}

2.1 Teachers' Personal Profile Out of the entire questionnaire filled in $60.7 \%$ was Aided higher secondary teachers and 39.3\% Government teachers. The percentage difference between Aided and Government teachers is more; this is due to the researcher more weigh given to Aided school teachers than Government teachers. Of the total teachers $56.1 \%$ were male and $43.9 \%$ female. The percentage difference between male and female teachers is less. Of the total teachers $31.1 \%$ were in above 50 years of age group, $46.3 \%$ were between $40-50$ years of age group, $20.9 \%$ were between $30-40$ years of age group and the remaining $1.6 \%$ in below 30 years of age. The percentage of third group is given more than other age group because those groups of teachers are facing more stress related problems in their profession as well as family.11.8\% teachers responded that they were unmarried and the remaining $88.2 \%$ were unmarried. The high percentages of unmarried teachers are having less stress than other groups like $40-50$ years of age group. With regards to monthly incomes, $50.2 \%$ of the teachers reported to receiving the monthly income are less than Rs.20, 000 and the remaining $49.8 \%$ are getting more than Rs.20, 000. The low percentages of income group of teachers are facing more stress related problems especially not settled in economically. From the years of teaching experience, 58.4\% those who have less than 15 years of experience are facing normal stress level and the remaining $41.6 \%$ of the teachers having more additional responsibilities in their profession and personal life. On the basis of subject handling, $64.5 \%$ those who are teaching in Science and vocational subjects are having more responsibilities than those who are teaching arts subjects $35.5 \%$. In Madurai district, $63.3 \%$ those who are working in rural areas are facing more social related problems in their profession than those who are working in urban areas (36.7\%).

\subsection{Measurement of Occupational Stress among Aided and Government School Teachers}

Table 1.2

Classification of higher secondary teachers (both government and aided) by their level of occupational stress)

\begin{tabular}{|c|c|c|c|}
\hline Sl.No. & Level of Stress & No. of Teachers & Percentage \\
\hline 1. & Low & 61 & 20.00 \\
\hline 2. & Medium & 190 & 62.30 \\
\hline 3. & High & 54 & 17.70 \\
\hline & Total & 305 & 100.00 \\
\hline
\end{tabular}

Source: Primary data.

From Table 1.2, it is observed that a majority of $190(62.30 \%)$ teachers had a medium level of stress, $61(20.0 \%)$ had a high level of stress and the remaining $54(17.7 \%)$ had a low level of stress.

\subsection{Level of Occupational Stress among Aided Higher Secondary School Teachers}

Table 1.3

Classification of aided higher secondary teachers by their level of occupational stress

\begin{tabular}{|c|c|c|c|}
\hline Sl.No. & Level of Stress & No. of Teachers & Percentage \\
\hline 1. & Low & 29 & 15.70 \\
\hline 2. & Medium & 77 & 41.60 \\
\hline 3. & High & 79 & 42.70 \\
\hline & Total & 185 & 100.00 \\
\hline
\end{tabular}

Source: Primary data.

Table 1.3 shows that 79 (42.70 per cent) aided teachers had a high level of occupational stress, 77 (41.60 per cent) had a medium level of stress and the remaining 29 (15.70 per cent) had a low level of occupational stress.

\section{Age And Level of Occupational Stress}

Table 1.4

Classification of Aided Higher Secondary Teachers on the basis of their Age and level of Occupational Stress

\begin{tabular}{|l|l|c|c|c|c|}
\hline \multirow{2}{*}{$\begin{array}{l}\text { Sl. } \\
\text { No. }\end{array}$} & \multicolumn{1}{|c|}{$\begin{array}{c}\text { Age } \\
\text { in years) }\end{array}$} & \multicolumn{3}{|c|}{ Level of Stress } & \multirow{2}{*}{ Total } \\
\cline { 2 - 5 } & Bow & Medium & High & \\
\hline 2. & $30-40$ & $0(0.0)$ & $2(1.1)$ & $0(0.0)$ & $2(1.1)$ \\
\hline 3. & $40-50$ & $1(0.5)$ & $25(13.5)$ & $11(5.9)$ & $37(20.00)$ \\
\hline 4. & Above 50 & $7(3.8)$ & $31(16.8)$ & $52(28.1)$ & $90(48.6)$ \\
\hline & Total & $21(11.4)$ & $19(10.3)$ & $16(8.6)$ & $56(30.3)$ \\
\hline
\end{tabular}

Source: Primary data. 
Note : Figures in brackets represent percentage to total.

Table 1.4 reveals that out of 2 (1.1 per cent) aided teachers, only 2 (1.1 per cent) had a medium level of stress in the age group of below 30 years. Of the 37 teachers, 1 ( 0.5 per cent) in the age group of 30-40 years had low level of stress, 25 (13.5 per cent) had a medium level stress and the remaining 11 (5.9 per cent) had a high level of stress.

Of the 90 teachers belong to the age group of 40-50 years, 7 (3.8 per cent) had a low level of stress, 31 (16.8 per cent) had a medium level of stress and the remaining 52 (28.1 per cent) had a high level of stress. Among the 56 teachers in to the age group of above 50 years, 21 (11.4 per cent) had a low level of stress, 19 (10.3 per cent) had a medium level of stress and the remaining 16 ( 8.6 per cent) had high level of stress.

To test the hypothesis that age is independent of the level of occupational stress, the chi-square test has been applied and the calculated value is 44.14 , table value at 5 per cent level of significance 9.488 and degrees of Freedom is 4 . As the calculated chi-square value is much larger than the table value, therefore the null hypothesis is rejected. Thus it may be concluded that there is a significant relationship between age and the level of stress among the aided higher secondary teachers.

\section{Gender And Level of Occupational Stress:}

Table 1.5

Classification of Aided Higher Secondary Teaches on the basis of their Gender and level of Occupational Stress

\begin{tabular}{|l|l|c|c|c|c|}
\hline \multirow{2}{*}{$\begin{array}{l}\text { Sl. } \\
\text { No. }\end{array}$} & \multirow{2}{*}{ Gender } & \multicolumn{3}{|c|}{ Level of Stress } & \multirow{2}{*}{ Total } \\
\cline { 2 - 5 } & Low & Medium & High & \\
\hline 1. & Male & $22(11.9)$ & $37(20.0)$ & $42(22.7)$ & $101(54.6)$ \\
\hline 2. & Female & $7(3.8)$ & $40(21.6)$ & $27(20.0)$ & $84(45.4)$ \\
\hline & Total & $29(15.7)$ & $77(41.6)$ & $79(42.7)$ & $185(100.0)$ \\
\hline
\end{tabular}

Source: Primary data.

Note : Figures in brackets represents percentage to total.

Table 1.5 shows that among the total teachers, 101 teachers were male, 22 (11.9 per cent) had a low level of stress, 37 (20.0 per cent) had a medium level of stress and the remaining 42 (22.7 per cent) had high level of stress. Of the 84 female teachers, 7 (3.8 per cent) had a low level of stress, 40 (21.6 per cent) had medium level of stress and the remaining 27 (20.0 per cent) teachers had a high level of stress. The chi-square test has been applied and the calculated value 6.69, table value at 5 per cent level of significance is 5.991 in degrees of freedom is 2 . As the calculated chi-square value is more than the table value the null hypothesis is rejected. Thus it may be concluded that there is an association between gender and their level of occupational stress among aided higher secondary teachers.

\section{Salary And Level of Occupational Stress:}

Table 1.6

Classification of Aided Higher Secondary Teachers on the basis of their Salary and level of Occupational Stress

\begin{tabular}{|c|c|c|c|c|c|}
\hline \multirow{2}{*}{$\begin{array}{l}\text { SI. } \\
\text { No. }\end{array}$} & \multirow{2}{*}{ Salary (in Rs.) } & \multicolumn{3}{|c|}{ Level of Stress } & \multirow{2}{*}{ Total } \\
\hline & & Low & Medium & High & \\
\hline 1. & Below 15000 & $2(1.1)$ & $5(2.7)$ & $10(5.4)$ & $17(9.2)$ \\
\hline 2. & $15000-20000$ & $3(1.6)$ & $36(19.5)$ & 39 (21.1) & $78(42.2)$ \\
\hline 3. & $20000-25000$ & $19(10.3)$ & $24(13.0)$ & $16(8.6)$ & 59 (31.9) \\
\hline 4. & Above 25000 & $5(2.7)$ & $12(6.5)$ & $14(7.6)$ & $31(16.8)$ \\
\hline & Total & $29(15.7)$ & 77 (41.6) & $79(42.7)$ & $185(100.0)$ \\
\hline
\end{tabular}

Source: Primary data.

Note : Figures in brackets represents percentage to total.

It could be inferred from Table 1.6 that of the total aided teachers, among 17 teachers who fall under the income group of below Rs.15,000, 2 (1.1 per cent) had a low level of stress, 5 (2.7 per cent) teachers had a medium level of stress and the remaining 10 (5.4 per cent) had a high level of stress.

Of the 78 teachers who fall under the income group of Rs.15, 000-20000, 3(1.6 per cent) teachers had a low level of stress, 36 (19.5 per cent) had a medium level of stress and the remaining 39 (21.1 per cent) had a high level of stress. Among fifty nine teachers who fall under the income group of Rs.20, 000-25000, 19 (10.3 per cent) had a low level of stress, 24 (13.0 per cent) had a medium level of stress and the remaining 16 (8.6 per cent) had a high level of stress. Of the teachers who fall under the income group of above Rs.25, 0005 (2.7 per cent) had a low level of stress, 12 (6.5 per cent) had a medium level of stress and the remaining 14 (7.6 per cent) 
had a high level of stress. The calculated value is 23.89; table value at 5 per cent level of significance 12.592 in degrees of freedom is 6 . As the calculated chi-square value is more than the table value, the null hypothesis is rejected. Therefore, it may be concluded that there is an association between the salary and their level of occupational stress among the aided higher secondary teachers.

\section{Years Of Experience And Level of Occupational Stress:}

Table 1.7

Classification of Aided Higher Secondary Teachers on the basis of their Years of Experience and level of Occupational Stress

\begin{tabular}{|l|l|c|c|c|c|}
\hline \multirow{2}{*}{$\begin{array}{l}\text { Sl. } \\
\text { No. }\end{array}$} & \multicolumn{1}{|c|}{$\begin{array}{c}\text { Teaching Experience } \\
\text { (in years) }\end{array}$} & \multicolumn{3}{|c|}{ Level of Stress } & \multirow{2}{*}{ Total } \\
\cline { 3 - 5 } & Lelow 5 & $2(1.1)$ & $3(1.6)$ & $11(5.9)$ & $16(8.6)$ \\
\hline 1. & $5-10$ & $1(0.5)$ & $19(10.3)$ & $14(7.6)$ & $34(18.4)$ \\
\hline 3. & $10-15$ & $10(5.4)$ & $19(10.3)$ & $15(8.1)$ & $44(23.8)$ \\
\hline 4. & Above 15 & $16(8.6)$ & $36(19.5)$ & $39(21.1)$ & $91(49.2)$ \\
\hline & Total & $29(15.7)$ & $77(41.6)$ & $79(42.7)$ & $185(100.0)$ \\
\hline
\end{tabular}

Source: Primary data.

Note : Figures in brackets represents percentage to total.

Table 1.7 shows that among the total aided school teachers, of the 16 who had the experience below 5 years, 2 (1.1 per cent) teachers had a low level of stress, 3 (1.6 per cent) had a medium level of stress and the remaining 11 (5.9 per cent) had high level of stress. Of the 34 teachers who had a years of experience between 5-10 years, 1 ( 0.5 per cent) teacher had a low level of stress, 19 (10.3 per cent) had a medium level and the remaining 14 ( 7.6 per cent) had a high level of stress. Among the 44 teachers who had a years of experience between 10-15 years, 10 (5.4 per cent) teachers had a low level of stress, 19 (10.3 per cent) had a medium level of stress and the remaining 15 (8.1 per cent) had a high level of stress. Out of 91 teachers who had a years of experience above 15 years, 16 (8.6 per cent) teachers had a low level of stress, 36 (19.5 per cent) had a medium level of stress and the remaining 39 (21.1 per cent) had a high level of stress. The calculated value is 12.84; table value at 5 per cent level of significance 12.592 in degrees of freedom is 6 . As the calculated chi-square value is larger than the table value, the null hypothesis is rejected. Therefore, it may be concluded that there is an association between years of experience and their level of occupational stress among the aided higher secondary teachers.

\section{Number of Dependents And Level of Occupational Stress:}

Table 1.8

Classification of Aided Higher Secondary Teachers on the basis of their Number of Dependents and level of Occupational Stress

\begin{tabular}{|l|l|c|c|c|c|}
\hline \multirow{2}{*}{$\begin{array}{l}\text { Sl. } \\
\text { No. }\end{array}$} & \multirow{2}{*}{ Number of Dependents } & \multicolumn{3}{|c|}{ Level of Stress } & \multirow{2}{*}{ Total } \\
\cline { 3 - 5 } & & Low & Medium & High & \\
\hline 1. & Below 3 & $11(9.4)$ & $32(27.4)$ & $34(29.1)$ & $77(65.8)$ \\
\hline 2. & $3-5$ & $3(2.6)$ & $20(17.1)$ & $4(3.4)$ & $27(23.1)$ \\
\hline 3. & Above 5 & $9(7.7)$ & $3(2.6)$ & $1(0.9)$ & $13(11.1)$ \\
\hline & Total & $23(15.7)$ & $55(41.6)$ & $39(42.7)$ & $117(100.0)$ \\
\hline
\end{tabular}

Source: Primary data.

Note : Figures in brackets represent percentage to total.

It is seen from Table 1.8 that of the total aided and government teachers, only 117 teachers are having dependents. Out of 77 aided teachers, who 11 (9.4 per cent) are having a dependents below 3, had a low level of stress, 32 (27.4 per cent) had medium level of stress and the remaining 34 (29.1 per cent) had high level of stress. Among the 27 teachers, 3 (2.6 per cent) who are having the number of dependents comprising 3-5 had low level of stress, 20 (17.1 per cent) had medium level of stress and the remaining 4 (3.4 per cent) had high level of stress. Of the 13 teachers, 9 ( 7.7 per cent) who are having the number of dependents above 5 had a low level of stress, 3 (2.6 per cent) had medium level and the remaining 1 ( 0.9 per cent) had high level of stress. The test has been applied and calculated value is 2.71 , table value at 5 per cent level of significance 9.488 in degrees of freedom 4. As the calculated chi-square value is more than the table value, the null hypothesis is rejected. Therefore, it may be concluded that there is an association between the number of dependents and their level of occupational stress among the aided higher secondary school teachers. 
Occupational Stress Among The Teachers Of The Higher Secondary Schools In Madurai District,

\section{Subjects Handling And Level of Occupational Stress:}

Table 1.9

Classification of Aided Higher Secondary Teachers on the basis of their Subjects handling and level of Occupational Stress

\begin{tabular}{|l|l|c|c|c|c|}
\hline \multirow{2}{*}{$\begin{array}{l}\text { Sl. } \\
\text { No. }\end{array}$} & \multirow{2}{*}{ Subjects Handling } & \multicolumn{3}{|c|}{ Level of Stress } & \multirow{2}{*}{ Total } \\
\cline { 3 - 5 } & & Low & Medium & High & \\
\hline 1. & Arts & $13(7.0)$ & $27(14.6)$ & $8(4.3)$ & $48(25.9)$ \\
\hline 2. & Science & $15(8.1)$ & $49(26.5)$ & $48(25.9)$ & $112(60.5)$ \\
\hline 3. & Vocational & $1(0.5)$ & $1(0.5)$ & $23(12.4)$ & $25(13.5)$ \\
\hline & Total & $29(15.7)$ & $77(41.6)$ & $79(42.7)$ & $185(100.0)$ \\
\hline
\end{tabular}

Source: Primary data.

Note : Figures in brackets represent percentage to total.

It is inferred from Table 1.9 that out of 48 teachers, 13 (7.0 per cent) who were handling Arts subjects had a low level of stress, 27 (14.6 per cent) had a medium level of stress and the remaining 8 (4.3 per cent) had a high level of stress. Of the 112 teachers, 15 (8.1 per cent) who were handling science subjects had a low level of stress, 49 (26.5 per cent) had medium level of stress and the remaining 48 (25.9 per cent) had high level of stress. Out of 25 teachers, 1 ( 0.5 per cent) handling vocational subjects had a low level of stress, 1 ( 0.5 per cent) had a medium level of stress and the remaining 23 (12.4 per cent) had a high level of stress. Chi-square test has been applied and the calculated value is 39.47 and table value at 5 per cent level of significance 9.488 in degrees of freedom is 4 . As the calculated chi-square value is more than the table value, the null hypothesis is rejected. Therefore, it may be concluded that there is an association between subjects handling and their level of occupational stress among the aided higher secondary school teachers.

\section{Location Of The School And Level of Occupational Stress:}

Table 1.10

Classification of Aided Higher Secondary Teachers on the basis of their School Location and level of Occupational Stress

\begin{tabular}{|l|l|c|c|c|c|}
\hline \multirow{2}{*}{$\begin{array}{l}\text { Sl. } \\
\text { No. }\end{array}$} & \multirow{2}{*}{ Location of School } & \multicolumn{3}{|c|}{ Level of Stress } & \multirow{2}{*}{ Total } \\
\cline { 3 - 5 } & & Low & Medium & High & \\
\hline 1. & Rural & $18(9.7)$ & $31(16.8)$ & $51(27.6)$ & $100(54.1)$ \\
\hline 2. & Urban & $9(4.9)$ & $21(11.4)$ & $9(4.9)$ & $39(21.1)$ \\
\hline 3. & Semi-Urban & $2(1.1)$ & $25(13.5)$ & $19(10.3)$ & $46(24.9)$ \\
\hline & Total & $29(15.7)$ & $77(41.6)$ & $79(42.7)$ & $185(100.0)$ \\
\hline
\end{tabular}

Source: Primary data.

Note : Figures in brackets represent percentage to total.

Table 1.10 shows that out of 100 aided school teachers, 18 (9.7 per cent) working in the schools located in rural areas had a low level of stress, 31 (16.8 per cent) had a medium level of stress and the remaining 51 (27.6 per cent) had a high level of stress. Of the 39 teachers working in urban areas, 9 (4.9 per cent) had a low level of stress, 21 (11.4 per cent) had a medium level of stress and the remaining 9 (4.9 per cent) had a high level of stress. Out of 46 teachers working in semi-urban areas, 2 ( 1.1 per cent) had a low level of stress, 25 (13.5 per cent) had a medium level of stress and 19 (10.3 per cent) had a high level of stress. The calculated value is 16.52 and table value at 5 per cent level of significance 9.488 in degrees of freedom is 4 . As the calculated chi-square value is more than the table, the null hypothesis is rejected. Therefore, it may be concluded that there is an association between location of school and their level of occupational stress among the aided higher secondary teachers.

\subsection{Level of Occupational Stress among Aided Higher Secondary School Teachers Level of Occupational Stress Among Government Higher Secondary School Teachers: \\ Table 1.12}

Classification of Government Higher Secondary Teachers by their level of Occupational Stress

\begin{tabular}{|l|c|c|c|}
\hline Sl.No. & Level of Stress & No. of Teachers & Percentage \\
\hline 1. & Low & 25 & 20.80 \\
\hline 2. & Medium & 76 & 63.30 \\
\hline 3. & High & 19 & 15.80 \\
\hline & Total & 120 & 100.00 \\
\hline
\end{tabular}

Source: Primary data. 
Table 1.12 explains that 76 (63.30 per cent) out of 120 government teachers, had a medium level of occupational stress, 25 teachers (20.80 per cent) had a low level of stress and the remaining 19 teachers (15.80 per cent) had a high level of occupational stress.

\section{Gender And Level of Occupational Stress:}

Table 1.13

Classification of Government Higher Secondary Teachers on the basis of their Gender and level of Occupational Stress

\begin{tabular}{|c|c|c|c|c|c|}
\hline \multirow{2}{*}{$\begin{array}{r}\text { Sl. } \\
\text { No. }\end{array}$} & \multirow{2}{*}{ Gender } & \multicolumn{3}{|c|}{ Level of Stress } & \multirow{2}{*}{ Total } \\
\hline & & Low & Medium & High & \\
\hline 1. & Male & $10(8.3)$ & $42(35.0)$ & $17(14.2)$ & $69(57.5)$ \\
\hline 2. & Female & $15(12.5)$ & $34(28.3)$ & $2(1.7)$ & $51(42.5)$ \\
\hline & Total & $25(20.8)$ & $76(63.3)$ & $19(15.8)$ & $120(100.0)$ \\
\hline
\end{tabular}

Source: Primary data.

Note : Figures in brackets represent percentage to total.

Table 1.13 shows that of the 69 male teachers, 10 (8.3 per cent) had a low level of stress, 42 (35.0 per cent) had a medium level of stress and the remaining 17 (14.2 per cent) had a high level of stress. Of the 51 female teachers, 15 (12.5 per cent) had a low level of stress, 34 (28.3 per cent) had a medium level of stress and the remaining 2 (1.7 per cent) had a high level of stress. The chi-square test has been applied and the result is 11.24 , table value at 5 per cent level of significance is 5.991 and degree of freedom is 2 . As the calculated chisquare value is more than the table, the null hypothesis is rejected. Therefore, it may be concluded that there is an association between gender and the level of occupational stress among the government higher secondary school teachers.

\section{Subjects Handling And Level of Occupational Stress:}

Table 1.14

Classification of Government Higher Secondary Teachers on the basis of their Subjects handling and level of Occupational Stress

\begin{tabular}{|l|l|c|c|c|c|}
\hline \multirow{2}{*}{$\begin{array}{l}\text { Sl. } \\
\text { No. }\end{array}$} & \multirow{2}{*}{ Subjects Handling } & \multicolumn{3}{|c|}{ Level of Stress } & \multirow{2}{*}{ Total } \\
\cline { 3 - 5 } & & Low & Medium & High & \\
\hline 1. & Arts & $12(10.1)$ & $37(31.1)$ & $11(9.2)$ & $60(50.0)$ \\
\hline 2. & Science & $13(10.9)$ & $23(19.3)$ & $3(2.5)$ & $39(32.5)$ \\
\hline 3. & Vocational & $0(0.0)$ & $16(13.3)$ & $5(4.2)$ & $21(17.5)$ \\
\hline & Total & $25(20.8)$ & $76(63.3)$ & $19(15.8)$ & $120(100.0)$ \\
\hline
\end{tabular}

Source: Primary data.

Note : Figures in brackets represents percentage to total.

Table 1.14 shows that out of 60 teachers, 12 (10.1 per cent) who were handling arts subjects had a low level of stress, 37 (31.1 per cent) had a medium level of stress and the remaining 11 (9.2 per cent) had the higher degree of stress. Out of 39 teachers, 13 (10.9 per cent) who were handling science subjects had a low level of stress, 23 (19.3 per cent) had a medium level of stress and the remaining 3 (2.5 per cent) had a higher degree of stress level. Of the 20 teachers, 16 (13.3 per cent) who were handling vocational subjects had a medium level of stress and the remaining 5 (4.2 per cent) had a higher degree of stress. Chi-square test has been applied, the result is 10.53 and table value at 5 per cent level of significance is 9.488 in degrees of freedom 4 . As the calculated chi-square value is more than the table value, the null hypothesis is rejected. Therefore, it may be concluded that there is an association between subjects handling and their level of occupational stress among government school teachers.

\subsection{Factor Analysis of Aided Higher Secondary Teacher}

For the present study, to find an important factor which would affect stress applied factor analsysis and found important variables below the table 1.11. It was identified as tool to identify suitable dimensions and related items. Data was ananlysed using principal component extraction with Data collected from 185 aided school teachers were subjected to principal - component factor analysis with Varimax Rotation by using the criterion that factors with Eigen value greater than 1.00 were retained. Loadings exceeding 0.4 were considered for determining the factors. 
Table 1.11

Statement Loadings of Occupational Stress Level For The Varimax Rotated Principal Components (185 Aided Teachers)

\begin{tabular}{|c|c|c|c|c|}
\hline Sl.No. & Statements & Loadings & $\begin{array}{l}\text { Eigen } \\
\text { Value }\end{array}$ & $\%$ of Variance \\
\hline 1 & Work is neither interesting nor prestigious. & 0.885 & 20.886 & 19.339 \\
\hline 2 & $\begin{array}{l}\text { Heavy and continuous noise in the premises creates } \\
\text { trouble. }\end{array}$ & 0.876 & 15.915 & 14.736 \\
\hline 3 & Good work for teacher's recognition. & 0.813 & 6.047 & 5.599 \\
\hline 4 & $\begin{array}{l}\text { Teachers are responsible for the features of a } \\
\text { number of teachers. }\end{array}$ & 0.837 & 5.516 & 5.107 \\
\hline 5 & $\begin{array}{l}\text { Lack of freedom to define one's job, otherwise, } \\
\text { would do differently from the way they do. }\end{array}$ & 0.737 & 4.757 & 4.405 \\
\hline 6 & $\begin{array}{l}\text { Co-operation among the staff helps to solve } \\
\text { administrative problems. }\end{array}$ & 0.788 & 4.733 & 4.382 \\
\hline 7 & $\begin{array}{l}\text { The new occupation demands training and expertise } \\
\text { of a new career. }\end{array}$ & 0.828 & 3.994 & 3.698 \\
\hline 8 & The teacher complicated problems. & 0.768 & 3.921 & 3.630 \\
\hline 9 & $\begin{array}{l}\text { Teacher get worried, they would not be able to } \\
\text { progress. }\end{array}$ & 0.701 & 3.847 & 3.562 \\
\hline 10 & $\begin{array}{l}\text { Institutional responsibilities interfere with extra } \\
\text { organisation career. }\end{array}$ & 0.785 & 3.370 & 3.121 \\
\hline 11 & $\begin{array}{l}\text { Teachers have given more importance in the } \\
\text { institution than others. }\end{array}$ & 0.841 & 3.284 & 3.041 \\
\hline 12 & $\begin{array}{l}\text { No free time to get refreshment and to prepare for } \\
\text { the next classes. }\end{array}$ & 0.857 & 3.086 & 2.857 \\
\hline 13 & Frequent transfer gives great trouble. & 0.815 & 2.987 & 2.765 \\
\hline 14 & $\begin{array}{l}\text { Mistakes of other teachers are shifted to the } \\
\text { shoulders and teachers who are free from defect. }\end{array}$ & 0.768 & 2.772 & 2.567 \\
\hline 15 & Family members interfere into career. & 0.572 & 2.430 & 2.250 \\
\hline 16 & $\begin{array}{l}\text { Seating arrangements in the class rooms are distract } \\
\text { and affect concentration. }\end{array}$ & 0.468 & 2.260 & 2.092 \\
\hline 17 & School is understaffed. & 0.729 & 2.111 & 1.955 \\
\hline 18 & $\begin{array}{l}\text { Peers, juniors demand in varying degrees which are } \\
\text { unable to satisfy. }\end{array}$ & 0.631 & 1.870 & 1.732 \\
\hline
\end{tabular}

\subsection{Factor Analysis of Government Higher Secondary Teacher}

For the present study, to find an important factor which would affect stress applied factor analsysis and found important variables below the table 1.15. It was identified as tool to identify suitable dimensions and related items. Data was ananlysed using principal component extraction with Data collected from 120 government school teachers were subjected to principal - component factor analysis with Varimax Rotation by using the criterion that factors with Eigen value greater than 1.00 were retained. Loadings exceeding 0.4 were considered for determining the factors.

Table 1.15

Statement Loadings of Occupational Stress Level For The Varimax Rotated Principal Components (185 Aided Teachers)

\begin{tabular}{|c|c|c|c|c|}
\hline $\begin{array}{l}\text { Sl. } \\
\text { No. }\end{array}$ & Statements & Loadings & $\begin{array}{l}\text { Eigen } \\
\text { Value }\end{array}$ & $\begin{array}{c}\% \text { of } \\
\text { Variance }\end{array}$ \\
\hline 1. & $\begin{array}{l}\text { Teaches cannot express their ability and competency } \\
\text { independently }\end{array}$ & 0.819 & 21.418 & 19.832 \\
\hline 2. & Lack of inner satisfaction through this work & 0.729 & 8.633 & 7.993 \\
\hline 3. & Job has enhanced social status & 0.714 & 6.008 & 5.563 \\
\hline 4. & Fairly old buildings mild panic all the time & 0.804 & 5.872 & 5.437 \\
\hline 5. & $\begin{array}{l}\text { Teachers who have less educational qualification get more } \\
\text { pay }\end{array}$ & 0.767 & 5.226 & 4.839 \\
\hline 6. & $\begin{array}{l}\text { Training programmes of the teachers are given their due } \\
\text { significance }\end{array}$ & 0.787 & 4.979 & 4.610 \\
\hline 7. & Teachers are doing the work with full responsibility & 0.777 & 3.580 & 3.315 \\
\hline 8. & Many problems working in rural areas & 0.716 & 3.285 & 3.042 \\
\hline 9. & Time limit to cover the syllabus and conduct test are not & 0.694 & 2.912 & 2.697 \\
\hline
\end{tabular}


Occupational Stress Among The Teachers Of The Higher Secondary Schools In Madurai District,

\begin{tabular}{|l|l|c|c|c|}
\hline & enough & & & \\
\hline 10. & Teaching gives all facility but not status & 0.740 & 2.875 & 2.662 \\
\hline 11. & Institutional responsibilities interfere extra organization & 0.621 & 2.757 & 2.553 \\
\hline 12. & $\begin{array}{l}\text { Exists sufficient and mutual co-operation and team spirit } \\
\text { among the teachers of the department }\end{array}$ & 0.699 & 2.676 & 2.477 \\
\hline 13. & No place of principle expressing honesty and equality & 0.630 & 2.610 & 2.417 \\
\hline 14. & Work load of the teacher is too heavy & 0.564 & 2.513 & 2.320 \\
\hline 15. & Career demands more consultation with other career & 0.478 & 2.189 & 2.026 \\
\hline
\end{tabular}

\section{Recommendations And Suggestions of Aided And Government Higher Secondary School} Teacher

\subsection{Aided Higher Secondary School Teachers}

Among the two designation groups aided school teachers, 14.6 per cent of those designated as teachers felt that the occupational stress level was extremely low.

Among the four age groups, 11.4 per cent of those above 50 years felt that the occupational stress level is extremely low.

Between the two gender groups, 11.9 per cent of those belonging to male group felt that the occupational stress level is extremely low.

Among the four salary groups, 10.3 per cent of those who fall under the group of Rs.20, 000-Rs.25, 000 felt that the occupational stress was extremely low.

Among the four experienced groups, 8.6 per cent of those fall under the teaching experience above 15 years felt that the occupational stress was extremely low.

Between the two marital status groups, 15.70 per cent of those who are unmarried felt that the occupational stress was extremely low.

Between the two family groups, 10.80 per cent of those who fall under the category of nuclear family felt that the stress level is low.

Among the aided school teachers with dependent, 9.40 per cent of those who have dependents below 3 felt that the occupational stress level is low.

Among the three subjects handling groups, 8.10 per cent of those who are handling science subjects felt that the occupational stress level is low.

Among the three groups, 9.00 per cent of those who have attended training programme above eight felt that the occupational stress level is low.

Among the three groups, 9.70 per cent of those who are working in the schools located at rural areas felt that the occupational stress level is low but higher than the other groups.

\subsection{Government Higher Secondary School Teacher}

Among the two designation groups of government school teachers, 19.20 per cent of teachers felt that the occupational stress level under government school was extremely low.

Among the four age groups 10.0 per cent of those who fall under the age group between 40-50 years who feel that the occupational stress is tolerable.

Between the two gender groups, 12.50 per cent of women teachers feel that the occupational stress level is low. It is higher than the others.

Among the four income groups, 8.30 per cent of those who fall under the monthly income between Rs.20, 000Rs.25, 000 whose opinion about the occupational stress level are low.

Among the four experience groups, 8.30 per cent of those who have the teaching experience between 5-10 years the occupational stress level are low.

Between the two marital status groups, 17.50 per cent of those belonging to unmarried felt that the occupational stress is low.

Between the two family groups, 14.20 per cent of those who fall under the category of nuclear family feel that the occupational stress level is low.

Among the three groups, 10.8 per cent of those who have dependents in the family comprising below 3 felt that the occupational stress level is low.

Among the three groups, 10.9 per cent of those who are handling science subjects felt that the occupational stress level is low.

Among the three training programme groups of teachers, 9.8 per cent of those who have attended the training programmes below 5 felt that the stress level in the school is low.

Among the three groups, 16.70 per cent of those whose schools are located at rural areas felt that the occupational stress level is low. 


\subsection{Suggestions}

Based on the findings of the study and from the opinions of the higher secondary school teachers, the following suggestions are made for due consideration and timely and suitable action by the authorities concerned.

It is found that the total teachers of government and aided schools (17.70 per cent) express that they had been victims of high level of occupational stress. Among the two cadres of higher secondary school teachers a high percentage of the aided school teachers (17.70 per cent) compared to government teachers $(15.80$ per cent) felt that the occupational stress level is high. It is perceived that, lack of interaction, time pressure for completing the syllabus, social status, heavy work load, poor working conditions, sufficient and mutual cooperations are the major sources of occupational stress. Hence it is suggested that the government and aided school recognize early the individual symptoms which cause occupational stress and take steps like counseling to reduce the occupational stress level.

Among the total teachers, 40-50 years of age group, had the medium and high level of stress. The government and aided higher secondary schools should be given normal workload, and by understanding their family responsibilities sympathetically their stress level could be considerably reduced.

The government and aided schools should try to offer transport facilities to the teachers who are coming from distant places so as to reduce the level of occupational stress.

The government and aided schools should often organize get together programmes and create good organizational climate in order to boost up the feelings of the teachers leading to reduction in occupational stress.

The government and aided schools should provide support (internally or externally) for teachers who have complex occupational stress issues.

The government and aided schools should provide teachers with opportunities to socialize issues pertaining to the teachers.

The government and aided schools should take steps to create interaction among the teachers and higher authorities. The government and aided schools, wherever possible, should give the teachers the chance to be involved in decisions and actions that affect their occupation.

The aided schools should follow directions of higher education department regarding recruitment, promotion, and termination of services of teachers.

The Government of Tamil Nadu should establish a separate Board for Higher Secondary Education.

The Government of Tamil Nadu Education Department should modify the structure of syllabus for all the disciplines.

The government and aided schools should provide job security to the teachers U/s 17(A) and 17(B).

The Education Department should restrict the student teacher ratio (1:40).

The government should provide medical facilities to the students as well as staff in a residential school.

The Government of Tamil Nadu and aided school management should jointly organise personality development courses, yoga courses and refresher courses for the teachers to enhance their personality traits and reduce their occupational stress.

It is found that the teachers are not happy with the lack of co-ordination among the staff. They should be provided practical training in human relations to achieve good rapport with their colleagues.

Aided school teachers have no possibility for transfer. At the same time the management can help them if it has got more than one school under its administration.

Aided school teachers feel that there is no possibility for promotional policy in the career development compared to the government teachers.

Aided school teachers personally feel that there is a lack of association for their activities, so the government should give permission to them to form unions to ventilate their grievances.

\subsection{Ways to Reduce Occupational Stress}

Through regular exercise, eating a healthy diet as occupational stress depletes vital nutrients, getting adequate rest, using tea and lunch break to read, listen to a relaxation $\mathrm{CD}$ or have a five-minute nap, playing relaxation music at home and burning aromatherapy oils, delegating responsibility wherever possible, taking time out to laugh by telling someone a joke, avoiding caffeine and sugar, taking time to do things that bring enjoyment and pleasure, making the good work environment, Hear relaxing sounds in the form of music or water fountain, keep a journal that monitors dates and times of stress to detect re-occurring patterns and to help you discover changes you may need to make. 


\section{Conclusion}

The present study has provided comprehensive information about occupational stress among the teachers of government and aided schools in Madurai district in the state of Tamil Nadu. Occupational stress in the workplace is becoming a major concern for all teachers, headmasters and government, owing to the occupational health and safety legislations requiring employers to practice 'duty of care' by providing teachers with safe working environments which also cover the psychological well being of their staff. The reduction of occupational stress will induce the teachers to provide efficient and effective service to the society. For the betterment of the educational institutions the occupational stress among the higher secondary school teachers should be reduced. As a result of the benefits of a systematic and joint approach to reducing stress there can be increased education standard, decrease in absenteeism, increased school's enrolment, reduced drop-out rate, improved teachers morale, decrease in compensation claim and reduction in workplace accidents. The most important benefit in reducing occupational stress is that it will promote a pleasurable work environment for all. The study throws light on the fact that occupational stress is quite a personal matter and that the perception of the situation enables one to cope with it effectively, being aware of the causes of occupational stress and monitoring properly.

\section{Books:}

\section{References}

[1] John Arnold, Iran Robertson, Carry T. Cooper, understanding human behaviour the work place -work psychology London Pitman Publishing pp.42-43, 1991.

\section{Journal Papers:}

[2] "Job Stress", Indian Journal of Industrial Relations, Vol-27, No.4, April 1992, p.397.

[3] T.A. Beehr, and J.E. Newman, "Job Stress, Employee Health and Organisational Effectiveness: A Facet Analysis, Model and Literature Review”, Personal Psychology, 31, 1978, pp.665-699.

[4] P. Weiskopf, “Burnout among Teachers of Exceptional Children” Exceptional Children, 47(1), 1980.

[5] L.S. Pettegrew, and G.E.Wolfe, Validating Measures of Teaches Stress, American Educational Research Journal, 19(3), 1982.

[6] W.G. Cunningham, "Teachers Burnout Solutions for the 1980's A Review of Literature”, Urban Review, 15 (1), 1983.

[7] A.G. Billings and R.H. Moss, "Coping, Stress and Social Resources among Adults with Unipolar Depression", Journal of Personality and Social Psychology, 46(4), 1984.

[8] M. Frese, "Stress at Work and Psychosomatic Complaints: A Causal Interpretation”, Journal of Applied Psychology, $70(2), 1985$.

[9] R. Manthei, and R. Solman, "Comparative Teachers Stress and Negative Outcomes in Canterbury State Schools", New Zealand Journal of Educational Studies, 2(2), 1988.

[10] U. Sharma, and S.Sharma, "Organizational Role Stress and Anxiety: A Comparative Study of Bureaucrats and Technocrats", Indian Journal of Industrial Relations, 24(3), 1989.

[11] C.M.B. Pierce, and G. Molloy, "Relations between School Type, Occupational Stress, Role Perceptions and Social Support", Australian Journal of Education, 34(3), 1990.

[12] D.O. Kaldenberg,. and B.W.Becker, "Work Load and Psychological Strain: A Test of the French Rodgers and Cobb Hypotheses", Journal of Organizational Behavior, 13, 1992.

[13] L.L. Morton, R.Vesco, N.H.Williams, and M.A, Awender, "Student Teacher Anxieties Related to Class Management, Pedagogy, Evaluation and Staff Relations", British Journal of Educational Psychology, 67, 1997.

[14] R.T. Pithers, and R. Soden, "Scottish and Australian Teachers Stress and Strain: A Comparative Study", British Journal of Educational Psychology, 681998.

[15] R. Lewis, "Teachers Coping with the Stress of Classroom Discipline”, Social Psychology of Education, $3,1999$.

[16] I.A Friedman, "Burnout in Teachers: Shattered Dreams of Impeccable Professional Performance", Journal of Clinical Psychology, 56, 2000.

[17] Z. Xiao, and Li, C. Woguo Jiaoshi, Xuyao Yanjiu Shuping (Teachers Needs in China)", Journal of Hebei Normal University (Educational Science Edition), No.3, 2003, 28-31.

[18] T Sargent, and E.Hannum, “Keeping Teachers Happy Job Satisfaction among Primary School Teachers in Rural Northwest China", Comparative Education Review, 49(2), 2005.

[19] N. Pande, and R.K.Naidu, "Effort and Outcome Orientations as Moderators of Stress - Strain Relationship”, Psychological Studies, 31(2), 1986.

[20] S.S. Jha, "Job Stress and Employee Strain in Indian Executives", Work and Stress, 2, 1988.

[21] V.S Reddy and P.V. Ramamurthy, "The Relation between Stress Experience on the Job-Age, Personality and General Ability", Psychological Studies, 36(2), 1991.

[22] T.R. Rajeswari, “Employee Stress: A Study with Reference to Bank Employees”, Indian Journal of Industrial Relations, 27(4), 1992.

[23] A.K.Singh, Sehgal, P. “Men and Women in Transition: Patterns of Stress, Strain and Social Relations”, Vikalpa, 20(1), pp.13-22, 1995.

[24] R. Lewis, “Teachers Coping with the Stress of Classroom Discipline”, Social Psychology of Education, 3, pp. 155-171, 1999.

[25] A Farooq. Shah, "Role Stress in the Indian Industry: A Study of Banking organizations", Indian journal of Industrial Relations, 38(3), pp.381-396, 2003.

[26] Berhem, Belal, Md Sidin, Samsinar and Syed Kadir, “A New Model for Work Stress Patterns”, Asian Academy of Management Journal, 9(1), pp.53-77, 2004.

[27] Lakwinder Singh Kang, "Stressors among Medical Representatives: An empirical Investigation”, Indian Journal of Industrial Relations, 40(3), pp.336-356, 2005.

[28] Anitha Devi, “Occupational Stress: A Comparative Study of Women in Different Occupations”, Trajan, 35(1), pp.61-73, $2006-07$.

[29] R.Dhanalakhsmi, "Factors Predicting Stress of Employees in a Public Transport Corporation”, SMART Journal of Business Management Studies, 4(1), pp.59-62, 2008. 